\title{
Firms' Export and Technological Innovation Decision from the Perspective of Financial Constrains: Evidence from Manufacturing Firms of Fujian Province
}

\author{
Han Yuanyuan ${ }^{1, ~ *, ~ Z h a o ~ J i n l i a n g ~}{ }^{2}$ \\ ${ }^{1}$ School of Economics and Finance, Huaqiao University, Quanzhou, China \\ ${ }^{2}$ Xiamen Branch, China Construction Bank, Xiamen, China \\ Email address: \\ hanyy@hqu.edu.cn (Han Yuanyuan), billzhaojl@126.com (Zhao Jinliang) \\ ${ }^{*}$ Corresponding author
}

\section{To cite this article:}

Han Yuanyuan, Zhao Jinliang. Firms' Export and Technological Innovation Decision from the Perspective of Financial Constrains: Evidence from Manufacturing Firms of Fujian Province. Science Innovation. Vol. 4, No. 2, 2016, pp. 99-104. doi: 10.11648/j.si.20160402.24

Received: April 4, 2016; Accepted: April 23, 2016; Published: May 5, 2016

\begin{abstract}
From the perspective of financial constraints, this article analysize the technological innovation decision of Fujian Province empirically using 2005-2007 micro firm data of the province under the formal and informal financing channels. We analyzed the influence of export trade, financial constraints on technology innovation. More important, the interaction between them. The results show that the financial constraints restrain the export of firms,thus affect the innovation decision, but the influence is quite different according to the different financing channels. Under the banks and other formal financing channels, the lower financial constraints of export firms, the stronger of its innovation propensity. But under the informal financing channels, trade credit has no significant effect on firms' innovation decision-making, nor affect firms' innovation through export mechanism.
\end{abstract}

Keywords: Financial Constraints, Firms' Innovation Decision, Export, Fujian Province

\section{融资约束视角下的企业出口与技术创新决定: 以中国福建省制造业企业为例}

\author{
韩媛媛 ${ }^{1, *}$, 赵金亮 ${ }^{2}$ \\ ${ }^{1}$ 经济与金融学院, 华侨大学, 泉州, 中国 \\ ${ }^{2}$ 厦门市分行, 中国建设银行, 厦门, 中国
}

\section{邮箱}

hanyy@hqu. edu. cn (韩媛媛)，billzhaoj1@126. com（赵金亮）

\begin{abstract}
摘要：本文从融资约束视角切入，在正式金融和非正式金融两个融资渠道下，采用2005-2007年微观企业数据，对中国 福建省企业技术创新的决定进行了实证分析。我们不仅分析了出口贸易、融资约束对技术创新的影响，还分析了两者 相互作用下的创新决定。研究结果表明融资约束阻碍了企业出口从而影响了企业的创新决策，但不同融资渠道下的这 一作用却相差迥异。在银行等正式金融下，融资约束程度越低的出口企业，其创新的倾向越高; 而在非正式金融下， 交易信贷本身不会对企业创新决策有显著作用，也没有通过出口机制进而影响企业创新。
\end{abstract}

关键词：融资约束，企业创新决策，出口，福建省 


\section{1. 引言}

企业技术创新是学界研究的永恒主题。众所周知, 技 术创新是转变经济增长方式、促进产业结构优化升级、提 升产业竞争力的有效途径, 更是福建省建设以其为核心的 海西经济区的重要举措, 因此加强技术创新对中国福建省 未来经济发展意义重大。福建省中小企业众多, 传统制造 业面临转型升级压力, 近期出台的福建省 “十三五规划” 中提出的第一个基本要求即是坚持创新, 以创新作为发展 基点, 促进并推动产业转型升级。《福建省企业技术创新 “十二五” 规划》中就曾指出, 企业应是技术创新的主体, 但福建省企业技术创新的一大问题是自主创新能力不足, 主体地位不突出, 技术对外依存度大, 多数企业生产的产 品缺乏核心技术。究其原因有创新投入不足、创新人才缺 之、创新机制不完善等。除此之外的另一重要原因是支持 技术创新的投融资环境没有得到显著改善。

中国是世界上融资约束最严重的国家之一，75\%的民 营企业都将融资约束视为企业发展的主要障碍 [1]。世界 银行 2009 年发布的题为《中国: 促进以企业为创新主题》 的研究报告中指出, 融资约束是阻碍私营企业创新的第二 大因素。1994年国务院开展了一项专门针对代表性省域福 建和甘肃两省企业技术创新的调研, 这是中国首次从微观 层面对工业企业技术创新研究较为深入全面的分析。通过 对调研数据的研究发现, 资金缺乏是阻碍企业技术创新的 首要因素, 其次是人才缺乏 [2]。2007年11月国务院发展 研究中心发表的一份题为《中国工业企业技术创新的阻碍 因素及对策建议》的研究报告中指出, 针对 2655 家大中 型工业企业技术创新的调查表明资金缺乏是阻碍企业技 术创新的主要的经济因素, 占到被调查企业的 $30 \%$ 左右。 可见, 多项调查研究均表明融资约束状况对企业技术创新 的影响不容忽视。

关于企业技术创新的研究可谓汗牛充栋, 但遗憾的是 迄今为止鲜有从融资约束视角切入考察者。而针对福建省 技术创新的研究大多也仅停留在宏观层面, 尚未有融资约 束视角下微观层面的探索。从企业微观层面看企业出口与 技术创新之间的关系如何? 在融资约束条件下这两者之 间的关系又如何? 不同融资渠道下这两者的关系有何差 别? 这正是本文所要解决的问题。因此, 本文使用中国福 建省企业层面的数据来深入探讨在融资约束条件下, 出口 贸易与民营企业创新之间的关系。

\section{2. 主要研究思路及相关文献综述}

企业异质性是国际贸易等领域所关注的热门论题, 其中也不乏从诸如企业规模、企业的年龄、所有权性质 等异质性角度探讨影响企业技术创新决策的研究。外部 融资约束是企业的另一重要特征, 是指外源性融资受到 限制和抑制。外源性融资是来源于企业之外的资金融通, 它对企业创新有着不可忽视的影响。不仅如此, 新兴贸 易理论的诸多理论与实证研究均表明融资约束阻碍企业 出口行为 [3] [4], 而出口贸易至今仍然是制造业企业提 升技术创新能力的重要来源, 因而融资约束理应还会通
过影响出口来影响创新决策。赵伟等（2013）借鉴 Gorodnichenko and Schnitzer (2010) 的模型 [5], 构 建了分析了中国制造业企业融资约束及出口与技术创新 的关系理论模型, 并对其进行了实证分析, 结果表明, 较易获得外部融资的企业更具有创新的能力和动力 [6]。 新近的研究如李后建、刘思亚 (2015) 对银行信贷、所 有权性质和企业创新之间的关系进行了实证分析, 文中 采用的是 2012 年世界银行关于中国企业运营的制度环 境质量调查数据, 结果表明银行信贷对企业创新具有显 著的积极影响。进一步地, 随着国有比例的增加, 银行 信贷对企业创新的积极影响会逐渐弱化 [7]。

企业可通过银行等正式金融和交易信贷等非正式金 融渠道进行融资。遗憾的是, 上述研究中融资约束更多的 是正式金融下的银行信贷的偏向所导致的, 却未曾提及非 正式金融的情况。可能的原因是长期以来非正规金融备受 理论界和决策部门的忽视甚至敌视。尽管如此, 非正规金 融活动并未因此而退出市场, 在某些地区 (如福建、浙江) 还呈进一步扩大之势。Allen et al. (2005) 等认为, 在 金融机制更加薄弱但发展迅速的私营企业中, 可能存在非 正式的融资渠道来替代正规融资渠道 [8]。事实上, 非正 式金融的确普遍存在。交易信贷是非正式金融的重要表现 形式之一，其在金融领域的相关研究中已经非常普遍，但 交易信贷与企业创新的关系被大多数人所忽略。Bönte and Nielen（2011）的研究表明交易信贷作为短期外部融 资方式的一种, 其对面临信贷约束的中小企业的创新, 尤 其是产品创新方面起到了积极的促进作用 [9]。赖永文等 （2012）对福建省非正规金融的基本情况和特点进行了分 析, 指出福建省非正规金融融资呈现覆盖范围扩大, 规模 增长的特点。早在 2011 年全省监测样本中共发生民间借贷 金额已达到 42.91 亿元 [10]。非正规金融是正规金融的有 益补充，但金融发展水平、产业结构等在地区之间差异较 大，非正规金融的作用在地区之间亦表现迥异，因而对该 地区企业的影响也不尽相同。具体到中国福建省而言, 究 竟非正式金融对企业创新有着怎样的影响呢? 因此, 本文 将在以下章节中从正式和非正式融资渠道分别探讨融资 约束、出口与技术创新的决策之间的关系。

\section{3. 模型设定、数据说明与变量描述}

\section{1 . 模型设定}

本文采用二元决策 Probit模型, 其形式设定如下:

$$
P\left[N E W_{\mathrm{it}}=1 \mid Z_{\mathrm{it}}\right]=\Phi\left[\beta^{\prime} Z_{\mathrm{it}}\right]
$$

其中, 对于上式中的 $\Phi[\cdot]$, 我们假定其为满足 $0<\Phi[\cdot]<1$ 的标准累积正态分布函数。

在充分借鉴国际已有理论和实证研究的基础上, 我们 结合中国现实背景以及实际所使用的数据样本, 设定了如 下形式的计量模型:

$$
P\left[N E W_{\mathrm{it}}=1 \mid Z_{\mathrm{it}}\right]=\Phi\left[\beta_{0}+\beta_{1} E X_{i t}+\beta_{2} I E_{i t}+\beta_{3} E X_{i t}^{*} I E_{i t}+\beta^{\prime} X_{i t}+\varepsilon_{i t}\right]
$$




\section{2. 数据来源及处理的说明}

本文使用的是2005-2007年间《中国工业企业数据库》， 这其中包含了全部的国有企业以及年产品销售收入在 500 万 元以上的非国有企业。根据新的企业登记注册类型代码, 将 企业类型分为: 国有、集体、私营、港澳台、外商投资及其 他六大类。本文将集体、私营企业两大类归为民营企业，作 为实证分析的主要考察对象。在数据样本的处理上, 以2000 年为基期对相关指标进行了价格指数平减。同时, 我们对样 本进行合理的篎选并对异常值、极端值等进行合理的删除。 具体而言, 删除了企业人数小于 10 、应收账款净额小于零以 及1949年之前成立的企业样本; 删除了企业年龄小于零、
2007年之后成立的企业、中间投入小于零、固定资产净值年 均余额小于零、工业增加值大于总产值、新产品产值小于零、 销售收入小于零、总产值小于固定资产、总资产小于流动资 产、累计折旧小于当年折旧以及省域代码的异常的样本观察 值等。另外, 为了使回归结果不受极端值的影响, 我们对所 有连续型解释变量在其分布的第1和第99百分位上的观察值 进行了缩尾 (Winsorize) 处理。

经过上述合理篎选后我们得到了41030个观察值的非 平衡面板数据, 对应了中国福建省的16916家企业, 下表1 从时间维度描述了该数据的结构。

表1 非平衡面板的数据结构。

\begin{tabular}{llll}
\hline 年份 & 观察值个数 & 百分比 & 累计百分比 \\
\hline 2005 & 12304 & $29.99 \%$ & $29.99 \%$ \\
2006 & 13666 & $33.31 \%$ & $63.30 \%$ \\
2007 & 15060 & $36.70 \%$ & $100.00 \%$ \\
\hline
\end{tabular}

值得一提的是, 本文所用的工业企业数据库中, 2000-2003年均没有应付账款这一指标，而2004年和2008 年的数据中虽有这个统计指标, 但缺失许多其他重要指标, 因此我们仅仅选取了 2005-2007年的数据进行实证分析。

\section{3. 变量的选取}

\section{3. 1. 被解释变量}

衡量企业创新的指标是多样的, 可分为投入类和产出 类, 前者主要是R\&D, 体现了创新的过程或来源, 后者有 新产品产值、发明专利数, 体现了创新的结果。本文根据 企业新产品销售产值是否为零设定被解释变量, 若企业销 售新产品产值大于零, 则表明企业从事技术创新, 否则则 没有技术创新。

\section{3.2. 解释变量}

首先, 本文关注的主要解释变量是融资约束。一般而 言, 企业的融资渠道分为内源性融资和外源性融资, 创新 融资也不外乎此。我们用企业利润率来表示 (企业利润与 企业规模的比值) 内源性融资。如前所述, 本文的融资约 束主要是指企业之外的融资渠道受到限制或抑制。目前中 国金融体系并不完善, 银行信贷仍然是企业进行外部融资 的主要渠道, 银行借贷融资在企业创新融资中发挥着极其 重要的角色。

孔祥贞等人（2013）在研究出口固定成本、融资约束 与中国企业出口参与时从内源融资、银行信贷和商业信贷 三个维度衡量融资约束 $[11]$, 而本文则主要关注的是外部 融资约束。因此, 本文借鉴Li 和Yu（2009）的方法, 并考 虑到融资约束数据的可得性, 我们采用利息支出来衡量正 式金融中的外源融资约束程度，同时为了控制企业规模因 素的影响, 我们以利息支出与企业规模的比值越高表示企 业越容易获得银行贷款, 从而外部融资约束程度越低 [12]。

另外, 关于非正式融资, 我们一般难以获得交易信贷 的准确数据。Ge and Qiu（2007）中使用了五个指标来衡 量交易信贷, 分别为企业应付账款与销售收入的比值、应
付账款与资产总值的比值、净应付账款（应付账款一应收 账款）与销售收入的比值、净应付账款与资产总值的比值 以及应付账款是否为零 [13]。而于洪霞等 (2011) 剔除了行 业差异采用应收账款相对比例来衡量交易信贷, 具体做法 是以某行业应收账款与销售收入比率的均值作为参照系, 以企业的应收账款与销售收入的比值除以这一均值来衡 量企业融资状况 [14]。本文根据所使用数据的可得性, 沿 用了 Ge and Qiu（2007）等的做法, 以企业的应付账款作 为交易信贷的代理变量。企业应付账款意味着企业在短期 内可以获得贸易伙伴的间接的信贷支持 [13]。

其次, 出口同样是我们关注的主要解释变量, 本文用 出口交货值是否为零来界定企业出口状态, 若出口交货值 大于零, 表明企业是出口企业; 否则, 则表明是非出口企 业。同时, 为了考察融资约束条件下, 出口与创新行为之 间的互动关系, 我们引入不同渠道的融资约束与出口的交 互项, 即 $\mathrm{EX} * \mathrm{AP}$ 和 $\mathrm{EX} * \mathrm{IE}$ 。若该交互项的系数为正, 表明融 资约束对出口企业的创新行为产生了促进作用; 若此交项 的系数为负, 则表明融资约束对出口企业的创新行为产生 了挤出效应。

\section{3. 3. 控制变量}

表2 研究变量名称及度量。

\begin{tabular}{|c|c|c|}
\hline 变量类别 & 变量名称 & 变量说明 \\
\hline \multirow[t]{4}{*}{ 被解释变量 } & $N E W$ & 技术创新 (新产品产值大于零 $=1$, 否则 $=0$ ) \\
\hline & $E X$ & 出口参与 $($ 出口 $=1$, 否则 $=0$ ) \\
\hline & SIZE & 企业规模=1n(年末从业人员) \\
\hline & $I E$ & 利息支出=1n（利息支出/企业规模） \\
\hline \multirow[t]{6}{*}{ 解释变量 } & $T C$ & $\mathrm{TC}=\ln$ (应付账款/企业规模) \\
\hline & PRO & 企业利润率 $=\ln ($ 利润水平/企业规模) \\
\hline & $I E \_E X$ & $E X * I E$ \\
\hline & $T C \_E X$ & $E X * T C$ \\
\hline & $A G E$ & 企业年龄=(当年年份-开业年份) \\
\hline & $K / L$ & 资本密集度=1n(K/L) \\
\hline \multirow[t]{3}{*}{ 控制变量 } & $I N D$ & 行业虚拟变量 \\
\hline & $R E G$ & 地区虚拟变量 \\
\hline & YEAR & 年度虚拟变量 \\
\hline
\end{tabular}


本文的控制变量包括企业规模 (SIZE)、企业年龄 (AGE) 以及资本密集度 $(\mathrm{K} / \mathrm{L})$ 等影响企业创新活动的其它因素, 以及地区 (REG) 、行业 (IND) 以及年份 (YEAR) 等虚拟 变量。其中, 企业规模用年末从业人员予以衡量, 资本密 集度是企业固定资产年均余额与年末从业人员的比值。详 细的变量说明可参见下表 2 。

\section{4. 变量的统计性描述和相关系数矩阵}

在对变量的选取及其预期符进行详细说明和初步判 断之后, 我们对主要变量进行了描述性统计, 具体如下 表3。
表3 主要研究变量的描述性统计。

\begin{tabular}{llllll}
\hline 变量 & 观察值 & 均值 & 标准差 & 最小值 & 最大值 \\
\hline NEW & 36570 & 0.0259776 & 0.1590705 & 0 & 1 \\
EX & 36570 & 0.3621001 & 0.4806141 & 0 & 1 \\
IE & 36570 & 0.6146141 & 0.8653684 & 0 & 3.697098 \\
TC & 36570 & 0.1168102 & 0.1281583 & 0 & 0.541258 \\
PR0 & 36570 & 2.172256 & 1.352507 & -0.8124939 & 5.623792 \\
SIZE & 36570 & 4.779943 & 1.062898 & 2.302585 & 9.980865 \\
AGE & 36570 & 8.50391 & 7.124125 & 1 & 142 \\
K/L & 36506 & 3.383358 & 1.475339 & -5.117994 & 10.3069 \\
\hline
\end{tabular}

考虑到各解释变量之间潜在的多重共线性问题, 我们 还列出了主要解释变量之间的Spearman相关系数矩阵, 详 见下表4:

表4 各主要解释变量的Spearman相关系数矩阵。

\begin{tabular}{lllllll}
\hline 变量名 & NEW & PR0 & IE & TC & EX & SIZE \\
\hline NEW & 1.0000 & & & & & \\
PRO & $0.0529 *$ & 1.0000 & & & & \\
IE & $0.0574 *$ & $0.1972 *$ & 1.0000 & & & \\
TC & $0.0286 *$ & $-0.0778 *$ & $-0.0548 *$ & 1.0000 & & \\
EX & $0.0789 *$ & $-0.1492 *$ & $-0.0772 *$ & $0.1097 *$ & 1.0000 & 1.0000 \\
SIZE & $0.1149 *$ & $-0.1575 *$ & $0.0503 *$ & $0.0875 *$ & $0.3251 *$ & $0.1505 *$ \\
AGE & $0.0487 *$ & $0.0179 *$ & $0.1141 *$ & $0.0396 *$ & $0.102 *$ & 1.0000 \\
K/L & $0.0334 *$ & $0.4122 *$ & $0.3863 *$ & $-0.1432 *$ & $-0.2341 *$ & $-0.2166 *$ \\
\hline
\end{tabular}

注: “*”表示在 $5 \%$ 的水平上显著。

从上表中的Sperman相关系数矩阵可以看出, 回归方程中的各主要解释变量之间并不存在多重共线性问题。紧接着, 我们将根据上述具体化的计量模型进行实证检验, 下面是相应的计量回归结果及相关分析。

\section{4. 实证结果的分析}

本文重点关注融资约束与出口对企业创新的影响，其中又将细分考察不同融资渠道下这种影响的区别，因此，实 证分析中将内源性融资和外源性融资同时纳入模型，但分别考察正式金融下的银行信贷以及非正式金融下的贸易信贷 的计量结果。具体的实证结果如下表所示:

表5 回归结果。

\begin{tabular}{|c|c|c|c|c|}
\hline & (1) & (2) & (3) & (4) \\
\hline & NEW & NEW & NEW & NEW \\
\hline \multirow[t]{2}{*}{ EX } & $0.0135^{* * * * *}$ & $0.00424^{*}$ & $0.0140^{* * * * *}$ & $0.0134^{* * * * *}$ \\
\hline & (0.00229) & (0.00233) & (0.00231) & (0.00288) \\
\hline \multirow[t]{2}{*}{ PRO } & $0.00276^{* * * *}$ & $0.00266^{* * * *}$ & $0.00290^{* \text { *apk }}$ & $0.00290^{* \text { **ak }}$ \\
\hline & (0.000576) & $(0.000584)$ & (0. 000569) & $(0.000569)$ \\
\hline \multirow[t]{2}{*}{ IE } & $0.00192^{* *}$ & -0.000821 & & \\
\hline & $(0.000820)$ & $(0.00101)$ & & \\
\hline IE*EX & & $\begin{array}{l}0.00800^{* * * *} \\
(0.00153)\end{array}$ & & \\
\hline \multirow[t]{2}{*}{$\mathrm{TC}$} & & & -0.00860 & -0.00991 \\
\hline & & & $(0.00537)$ & $(0.00696)$ \\
\hline \multirow[t]{2}{*}{$\mathrm{TC} * \mathrm{EX}$} & & & & 0.00334 \\
\hline & & & & $(0.0100)$ \\
\hline \multirow[t]{2}{*}{ SIZE } & $0.00864^{* \text { *ak }}$ & $0.00857^{* * * *}$ & $0.00879^{* * * * *}$ & $0.00879^{* * * k}$ \\
\hline & (0.000693) & $(0.000686)$ & (0.000694) & $(0.000695)$ \\
\hline \multirow[t]{2}{*}{ AGE } & $0.000339^{* * * * *}$ & $0.000315^{* * * *}$ & $0.000352^{* * a k}$ & $0.000353^{* * *}$ \\
\hline & $(0.0000749)$ & (0.0000796) & (0.0000743) & (0. 0000743) \\
\hline \multirow[t]{2}{*}{$\mathrm{K} / \mathrm{L}$} & $0.00225^{\text {*atk }}$ & $0.00214^{* * a k}$ & $0.00265^{\text {*ate }}$ & $0.00265^{* * * *}$ \\
\hline & (0.000665) & $(0.000661)$ & (0.000628) & $(0.000628)$ \\
\hline$N$ & 21190 & 21190 & 21190 & 21190 \\
\hline
\end{tabular}




\begin{tabular}{lllll}
\hline & $(1)$ & $(2)$ & $(3)$ & $(4)$ \\
\hline & NEW & NEW & NEW & NEW \\
\hline pseudo $R^{2}$ & 0.200 & 0.206 & 0.199 & 0.199 \\
Log 1ik. & -1921.0 & -1905.6 & -1922.5 & -1922.4 \\
Chi-squared & 795.2 & 850.0 & 795.5 & 795.4 \\
p & $1.70 \mathrm{e}-138$ & $3.77 \mathrm{e}-149$ & $1.47 \mathrm{e}-138$ & $6.63 \mathrm{e}-138$ \\
\hline
\end{tabular}

注: 括号内数值为稳健标准误，*、**、***分别表示参数的估计值在 $10 \% 、 5 \% 、 1 \%$ 的水平上显著; 此外，我们还对企业所属的行业、区域以及年份 虚拟变量进行了控制。

\section{1. 内源融资的分析结果}

从以上结果来看, 企业利润率对其创新决策的影响始 终是显著为正, 这也就意味着无论是正式金融还是非正式 金融下，企业内源性融资对其创新决策都是十分重要的。 根据Myers and Majluf（1984）的融资次序理论, 企业首 先是运用内部现金流来进行创新的融资。内部现金流是企 业做出创新努力的重要激励因素, 即企业在内部现金流充 足的情况下, 才会考虑进行研发投入。企业利润率高, 意 味着企业能够积累内部现金流，那么其创新倾向就高。正 如国务院一份研究报告中指出的那样内部资金不足和创新 成本高是阻碍中国大中型工业企业创新的重要的经济因素。

\section{2. 外源性融资之正式金融下的银行信贷的分析结果}

从模型（1）的计量结果可知，银行等金融机构的间 接融资对企业创新具有正向促进作用, 即融资约束越小, 企业创新倾向越高。但当我们加入交互项后, 如模型 (2) 的结果所示, 外部融资约束对创新的影响不再显著, 但是 从交叉项的结果却在 $5 \%$ 的水平下显著为正。交叉项的系数 显著为正值, 说明利息支出占比越大, 融资约束越小, 出 口对企业创新倾向的影响越大, 即融资约束越低, 出口对 创新的影响越强。同时, 这意味着外部融资约束对创新的 影响的机制是通过出口来实现的。即在出口企业中, 融资 约束越小, 创新的倾向越高, 这正是Mannov (2011) 的研 究所证实的融资约束会阻碍企业出口 [15], 从而进一步阻 碍了企业的创新决策。或也可以理解为由于融资约束的存 在, 减弱了出口对创新的影响。

\section{3. 外源融资之非正式金融下的分析结果}

从模型（3）和模型（4）的实证结果可知, 交易信贷 本身对企业创新没有显著的作用, 也没有通过出口环节影 响企业创新。究其可能的原因应该是多方面的。其一, 创 新活动本身从投入到产出是长期作用的结果，而交易信贷 本身是一种短期融资, 不足以支撑企业去创新。其二, 私 营企业多数是中小企业甚至是微型企业, 其本身内源融资 不足, 此时得到的外部融资很有可能是支撑企业正常周转 运行的。其三, 中国福建省金融发展相对落后, 非正式金 融中民间借贷占多数, 而缺乏其他类型的有益补充。

\section{4. 其他变量的分析结果}

其他变量如企业规模、企业年龄以及资本密集度完全 符合预期, 对企业创新决策均是正的影响。具体而言, 企 业规模越大, 创新倾向越高。企业存活时间越久, 证明它 的能力越强, 积累的经验越丰富, 创新倾向越高。同时,
只有创新倾向高的企业它才能存活时间更久。企业资本相 对于劳动密集度本身就是可以衡量了企业的资金状况, 因 此, 密集度越高, 创新倾向也越高。

\section{5. 结论}

本文从融资约束视角切入，在正式金融和非正式金融 两个融资渠道下, 采用2005-2007年微观企业数据对中国 福建省企业技术创新的决定进行了理论和实证分析。我们 不仅分析了出口贸易、融资约束对技术创新的影响, 还分 析了两者相互作用下的创新决定。得出的主要结论有二:

其一, 在影响技术创新决策的诸因素中, 出口贸易和 企业内源融资都对企业技术创新的决定起着显著的促进 作用。从事出口的企业更容易从外部市场获取技术创新的 信息, 而内源性融资是企业创新的支撑和动力。其二, 融 资约束阻碍了企业出口从而影响了企业的创新决策, 但不 同融资渠道下的这一作用却相差迥异。银行等正式金融下, 融资约束程度越低的出口企业, 其创新的倾向越强。而在 非正式金融下, 交易信贷本身不会对企业创新决策有显著 作用, 也没有通过出口环节影响企业创新。

据此，我们的政策启示是：首先，中国福建省政府应 该继续鼓励企业出口, 尤其是鼓励以技术创新为导向的企 业参与国际市场, 在原有培育重点出口商品基地的基础上, 培育更多的技术创新型出口企业。其次, 促进企业创新须 更加关注金融市场的发展。对于出口企业而言, 尤其是民 营的出口企业, 融资约束的存在会对他们的创新产生 “挤 出效应”。因此，政府应该大力支持民营企业，取消对民 营企业融资的诸多限制, 引导金融资源与民营创新企业相 结合。同时, 还应该鼓励非正规金融的存在, 采取合理措 施让非正规金融成为正规金融的有益补充。

\section{致谢}

本文为中国福建省软科学项目《融资约束视角下的出 口与企业技术创新研究——基于福建省制造业企业的分 析》(2014R0067) 的阶段性成果之一。

\section{参考文献}

[1] Claessens, S., K. Tzioumis., Measuring firms' access to finance, Mineo, World Bank. 2006.

[2] 邓寿鹏. 2000家企业技术创新的实证调查 [J]. 中国科技产 业1996 (2):8-10。 
[3] Chaney, T., Liquidity constrained exporters [0L]. Working paper, Department of Economics, University of Chicago, IL , 2005.

[4] Manova, K., Credit Constraints, Heterogeneity of Firms and International Trade [OL]. NBER working paper No. 14531, 2008.

[5] Gorodnichenko and Schnitzer, Financial constraints and innovation: Why poor countries don' t catch up [OL]. NBER Working Papers , 2010, No: 15792.

６］赵伟、韩媛媛、赵金亮. 融资约束、出口与中国本土企业创 新：机理与实证 $[J]$. 当代经济科学，2012（6）：98-108。

[7] 李后建、刘思亚. 银行信贷、所有权性质与企业创新 [J]. 科 学学研究, 2015(7)：1089-1099。

[8] Allen, F., J. Qian and M. Qian, Law, Finance and Economic Growth in China [J]. Journal of Financial Economics, 2005, 77: 57-116.

[9] Bönte W. and Nielen S., Product Innovation, Credit Constraints and Trade Credit: Evidence from a
Cross-country Study [OL]. Manage. Decis. Econ. 2011, 32: 413-424.

[10］赖永文、沈理明、林路曦. 福建省非正规金融变迁、效应及 规范发展 $[J]$. 福建金融，2012（8）：17-21.

[11] 孔祥贞、刘海洋、徐大伟. 出口固定成本、融资约束与中 国企业出口参与 $[J]$. 世界经济研究, 2013(4)。

[12] Li Zhiyuan and Yu Miaojie. Exports, Productivity, and Credit Constraints: A Firm-Level Empirical Investigation of China [OL]. CCER Working Paper, No. 2009005.

[13] Ge Ying, Qiu Jiaping, Financial development, bank discrimination and trade credit $[\mathrm{J}]$. Journal of Banking and Finance, 2007, 31(2) :513-530.

[14] 于洪霞、龚六堂、陈玉宇. 出口固定成本融资约束与企业出 口行为 $[J]$. 经济研究, 2011（4）：55-67。

[15] Manova, K., S. -J. Wei and Z. Zhang., Firm Exports and Multinational Activity under Credit Constraints [0L]. NBER working paper No. 16905, 2011. 